CLINICAL STUDY

\title{
Low-dose dexamethasone administration for 3 weeks favorably affects plasma HDL concentration and composition but does not affect very low-density lipoprotein kinetics
}

\author{
Xuewen Wang, Faidon Magkos, Bruce W Patterson, Dominic N Reeds, Janine Kampelman and Bettina Mittendorfer \\ Division of Geriatrics and Nutritional Science, Washington University School of Medicine, Center for Human Nutrition, 660 S. Euclid Avenue, Campus Box \\ 8031, St Louis, Missouri 63110, USA
}

(Correspondence should be addressed to B Mittendorfer; Email: mittendb@wustl.edu)

\begin{abstract}
Objective: Subclinical hypercortisolemia often occurs in subjects with features of the metabolic syndrome, and it has been suggested that it may be, at least in part, responsible for the development of these metabolic abnormalities. However, the metabolic effects of glucocorticoid administration to mimic subclinical glucocorticoid excess have not been evaluated.

Methods: We used stable isotope-labeled tracer methods in conjunction with magnetic resonance techniques to measure the effect of glucocorticoid excess within the physiological range $(\sim 0.7 \mathrm{mg}$ dexamethasone/day for 3 weeks) on glucose and free fatty acid (FFA) rates of appearance (Ra) into plasma, intrahepatic triglyceride (TG) content, very low-density lipoprotein (VLDL)-TG and VLDLapolipoprotein B-100 (apoB-100) kinetics and plasma lipoprotein subclass concentrations, and particle sizes in nine overweight and obese individuals.

Results: Dexamethasone treatment led to a very small but significant increase in body weight (from $87.4 \pm 7.1$ to $88.6 \pm 7.2 \mathrm{~kg} ; P=0.003$ ) and increased HDL-cholesterol (from $45.9 \pm 2.8$ to $55.1 \pm$ $4.6 \mathrm{mg} / \mathrm{dl} ; P=0.037$ ) and HDL particle (from $33.7 \pm 2.2$ to $41.4 \pm 4.2 \mathrm{nmol} / \mathrm{l} ; \quad P=0.023$ ) concentrations in plasma but had no effect on intrahepatic TG content, glucose and FFA Ra in plasma, hepatic VLDL-TG and VLDL-apoB-100 secretion rates and mean residence times in the circulation, plasma TG and LDL-cholesterol concentrations, and plasma lipoprotein particle sizes. Conclusion: Subclinical hypercortisolemia does not have significant adverse metabolic consequences.
\end{abstract}

European Journal of Endocrinology 167 217-223

\section{Introduction}

Chronic endogenous glucocorticoid excess in persons with Cushing's disease is associated with metabolic dysfunction characterized by central obesity, insulin resistance, and dyslipidemia (increased fasting plasma triglyceride (TG) and total and LDL-cholesterol concentrations and decreased HDL-cholesterol concentration) (1). Subclinical hypercortisolemia often occurs in subjects with features of the metabolic syndrome, and it has been suggested that it may be, at least in part, responsible for the development of these metabolic abnormalities in obese subjects $(2,3)$. The effect of increased glucocorticoid receptor activity on metabolism, however, is unclear. Experimental administration of supraphysiological doses of glucocorticoids increases plasma free fatty acid (FFA) availability in the systemic circulation $(3,4,5)$. Increased plasma FFA availability can lead to ectopic fat deposition in the liver and skeletal muscle, attenuation of hepatic and skeletal muscle insulin action (resulting in hyperglycemia and hyperinsulinemia), and stimulation of hepatic very low-density lipoprotein (VLDL) secretion and hypertriglyceridemia $(3,6,7)$. Nevertheless, chronic glucocorticoid administration in patients with obstructive pulmonary conditions and rheumatic diseases has no effect on plasma TG, LDL-cholesterol, and apolipoprotein B-100 (apoB-100) concentrations but increases HDL-cholesterol and apolipoprotein A-I (apoA-I) concentrations $(8,9,10,11)$. This, however, may be the result of the potent anti-inflammatory and immunosuppressive actions of glucocorticoids, which may blunt their potential adverse metabolic effects. The apparent discrepancy in the findings could also be due to differences in subject characteristics between studies because the results from studies on rats suggest that obese rats are more sensitive to the effects of cortisol on plasma TG metabolism than lean ones $(12,13)$. The metabolic effects of glucocorticoid administration in very low doses to mimic subclinical glucocorticoid excess that is associated with the metabolic syndrome in obese subjects are not known. 
We therefore used a combination of stable isotopically labeled tracer and nuclear magnetic resonance techniques to evaluate the effect of chronic glucocorticoid excess on: i) peripheral adipose tissue lipolysis (FFA rate of appearance (Ra) in plasma); ii) intrahepatic TG content; iii) hepatic VLDL-TG and VLDL-apoB-100 secretion rates and VLDL-TG and VLDL-apoB-100 mean residence times in the circulation; iv) hepatic glucose production rate and hepatic insulin sensitivity (hepatic insulin sensitivity index, HISI); and v) plasma lipoprotein subclass concentrations and particle sizes in overweight and obese but otherwise healthy (i.e. no evidence of features of the metabolic syndrome) individuals.

\section{Materials and methods}

\section{Subjects}

Nine individuals (six women and three men; age: $40.8 \pm 4.4$ years; body mass index: $31.7 \pm 2.0 \mathrm{~kg} / \mathrm{m}^{2}$; percent body fat: $35.0 \pm 2.6 \%$; mean \pm s.E.M.) volunteered for the study. All subjects completed a comprehensive medical examination, which included a detailed history and physical examination, a resting electrocardiogram, standard blood tests, and an oral glucose tolerance test. None of the subjects had elevated morning plasma cortisol concentrations or signs of hypercortisolemia, evidence of illness, or were taking medications known to affect carbohydrate or lipid metabolism. Body composition was determined by using dual-energy X-ray absorptiometry (Hologic QDR 1000/w; Hologic, Inc., Waltham, MA, USA). The study was approved by the Institutional Review Board of Washington University School of Medicine in St Louis. Written informed consent was obtained from all subjects before participation in the study.

\section{Experimental protocol}

All subjects completed two metabolic studies: one before and one after low-dose dexamethasone administration for 3 weeks $(0.013 \mathrm{mg} / \mathrm{kg}$ fat-free mass daily). The specified dose of dexamethasone $(\sim 0.7 \mathrm{mg} /$ day $)$ is equivalent to $\sim 20 \mathrm{mg} /$ day hydrocortisone, the dose clinically used for glucocorticoid replacement therapy (14). Before and on the last day of treatment, subjects were admitted to the Clinical Research Unit in the late afternoon. At $1900 \mathrm{~h}$, they consumed a standard meal containing $12 \mathrm{kcal} / \mathrm{kg}$ adjusted body weight (15): 55\% of total energy was provided as carbohydrate, $30 \%$ as fat, and $15 \%$ as protein. Subjects then rested in bed and fasted (except for water) until completion of the study the next day.

The following morning, at $\sim 0530 \mathrm{~h}$, one catheter was inserted into a forearm vein to administer stable isotope-labeled tracers (purchased from Cambridge
Isotope Laboratories, Andover, MA, USA) and a second catheter was inserted into a contralateral hand vein to obtain arterialized blood samples by heating the hand to $55^{\circ} \mathrm{C}$ using a thermostatically controlled box. Blood samples were obtained immediately before the tracer administration to determine plasma substrate, insulin and cytokine concentrations, and background glycerol, palmitate, and leucine tracer-to-tracee ratio (TTR). At $0700 \mathrm{~h}$, a bolus of $0.9 \% \mathrm{NaCl}$ solution containing $\left[1,1,2,3,3-{ }^{2} \mathrm{H}_{5}\right]$ glycerol $(50 \mu \mathrm{mol} / \mathrm{kg}$ body weight), $\left[5,5,5-{ }^{2} \mathrm{H}_{3}\right]$ leucine $(7.2 \mu \mathrm{mol} / \mathrm{kg})$, and $\left[6,6-{ }^{2} \mathrm{H}_{2}\right]$ glucose $(22 \mu \mathrm{mol} / \mathrm{kg})$ was administered through the catheter in the forearm vein, followed by constant infusions of $\left[5,5,5-{ }^{2} \mathrm{H}_{3}\right]$ leucine $(0.12 \mu \mathrm{mol} / \mathrm{kg}$ per min for $12 \mathrm{~h})$ and $\left[6,6-{ }^{2} \mathrm{H}_{2}\right]$ glucose $(0.22 \mu \mathrm{mol} / \mathrm{kg}$ per $\min$ for $4 \mathrm{~h})$, dissolved in $0.9 \% \mathrm{NaCl}$ solution, and $\left[2,2-{ }^{2} \mathrm{H}_{2}\right]$ palmitate $(0.035 \mu \mathrm{mol} / \mathrm{kg}$ per min for $12 \mathrm{~h})$, dissolved in $25 \%$ human albumin solution. Blood samples were obtained at 5, 15, 30, 60, 90, and $120 \mathrm{~min}$ and then every hour for $10 \mathrm{~h}$ to determine free glycerol, glucose, palmitate, and leucine TTRs in plasma and in VLDL-TG and VLDLapoB-100. Intrahepatic TG content was determined by using magnetic resonance spectroscopy (3T Siemens Magnetom Trio scanner; Siemens, Erlanger, Germany).

\section{Sample collection and storage}

Blood samples were collected in chilled tubes containing EDTA to determine plasma lipid concentrations and substrate TTRs. To determine plasma glucose, insulin, and cytokine concentrations, blood samples were collected in chilled tubes containing heparin. Samples were placed on ice and plasma was separated by centrifugation within $30 \mathrm{~min}$ of collection. Aliquots of plasma were kept in the refrigerator for immediate isolation of VLDL and measurement of plasma apoB100 concentration. The remaining plasma samples were stored at $-80{ }^{\circ} \mathrm{C}$ until the final analyses were performed. The VLDL fraction was isolated from plasma by ultracentrifugation $(16,17)$. Aliquots of the VLDL fraction were used for measuring VLDL-apoB-100 concentration immediately after collection; the remaining samples were stored at $-80^{\circ} \mathrm{C}$ until final analyses.

\section{Sample processing and analyses}

Plasma concentrations of total TG, total cholesterol, HDL-cholesterol, and LDL-cholesterol were measured by standard hospital laboratory methods using a Hitachi 917 autoanalyzer (Hitachi). Plasma lipoprotein particle concentrations and average lipoprotein sizes were determined by using proton nuclear magnetic resonance spectroscopy (LipoScience, Raleigh, NC, USA) $(18,19)$.

Plasma glucose concentration was determined by using an automated glucose analyzer (YSI 2300 STAT plus; Yellow Springs Instrument Co., Yellow Springs, $\mathrm{OH}, \mathrm{USA})$. Plasma insulin concentration was measured 
by using an automated chemiluminescent immunoanalyzer (IMMULITE; Siemens Healthcare Diagnostic, Los Angeles, CA, USA). Plasma-FFA concentrations were quantified by gas chromatography (GC; HewlettPackard 5890-II, Palo Alto, CA, USA) after adding heptadecanoic acid to plasma as an internal standard (20). Plasma apoB-100 and VLDL-apoB-100 concentrations were measured by using a turbidimetric immunoassay (Kamiya Biomedical Co., Seattle, WA, USA). VLDL-TG concentration was measured by using a colorimetric enzymatic kit (Sigma-Aldrich Co.). The concentrations of tumor necrosis factor alpha (TNF- $\alpha$ ), interleukin 6 (IL6), and cortisol were measured by using commercially available ELISAs (R\&D Systems, Minneapolis, MN, USA). Plasma ACTH concentration was measured by using a commercially available immunoassay on the Immulite 2000 system at the Mayo Clinic in Rochester, MN, USA.

The TTRs of glycerol, palmitate, leucine, and glucose in plasma, glycerol and palmitate in VLDL-TG, and leucine in VLDL-apoB-100 were determined by GC-mass spectrometry (MS; MSD 5973 System, Hewlett-Packard) as described previously $(16,17,20$, $21,22)$. Plasma-free palmitate and palmitate in VLDL-TG were analyzed as methylesters. The heptafluorobutyryl derivative was formed for the analysis of glycerol and glucose in plasma and glycerol in VLDL-TG, the $N$-heptafluorobutyryl $n$-propyl ester derivative was used for leucine in VLDL-apoB-100, and the $t$-butyldimethylsilyl derivative was used for free leucine in plasma.

\section{Calculations}

The fractional turnover rate (FTR) of VLDL-TG and VLDL-apoB-100 was determined by fitting the glycerol and leucine TTR time courses in plasma and VLDL-TG and VLDL-apoB-100 respectively, to multicompartmental models as described previously $(16,17,21,22)$. The secretion rates of VLDL-TG ( $\mu \mathrm{mol} / \mathrm{l}$ plasma per min) and VLDL-apoB-100 (nmol/l plasma per min), which represent the amount of VLDL-TG and VLDL-apoB-100 (i.e. VLDL particles) secreted by the liver per unit of plasma, were calculated by multiplying the FTR of VLDL-TG and VLDL-apoB-100 (pools/min) by the plasma concentrations of VLDL-TG $(\mu \mathrm{mol} / \mathrm{l})$ and VLDL-apoB-100 $(\mathrm{nmol} / \mathrm{l})$ respectively. The mean residence times (MRT) of VLDL-TG and VLDL-apoB-100, which represent the time VLDL-TG and VLDL-apoB-100 remain in the circulation after secretion by the liver, were calculated as 1/FTR.

Palmitate Ra in plasma was calculated by dividing the palmitate tracer infusion rate by the average plasma palmitate TTR value between 60 and $240 \mathrm{~min}$. Total FFA Ra was calculated by dividing palmitate Ra by the proportional contribution of palmitate to total plasma FFA concentration (23). The relative contribution of systemic plasma FFA and nonsystemic fatty acids to total VLDL-TG production was calculated on the basis of isotopic dilution upon fitting the palmitate TTR in plasma and VLDL-TG to a multicompartmental model $(16,17,22)$. Nonsystemic fatty acids in VLDL-TG are derived from the pools of fatty acids that are not labeled with tracer during the infusion period, including fatty acids derived from: i) lipolysis of preexisting, slowly turning over lipid stores in the liver and tissues draining directly into the portal vein; ii) lipolysis of plasma lipoproteins that are taken up by the liver; and iii) hepatic de novo lipogenesis.

Glucose Ra into plasma was calculated by dividing the glucose tracer infusion rate by the average plasma glucose TTR between 210 and 300 min (22). The HISI was calculated as the inverse of the product of glucose $\mathrm{Ra}$ and plasma insulin concentration $(24,25)$. The adipose tissue insulin sensitivity index (ATISI) was calculated as the inverse of the product of FFA Ra and plasma insulin concentration (26).

\section{Statistical analysis}

Analyses were performed using SPSS 20 (IBM SPSS, Chicago, IL, USA). Normally distributed data are expressed as mean \pm s.E.M. and Student's paired $t$-test was used to compare the results before and after dexamethasone treatment. Skewed data are expressed as medians and quartiles, and Wilcoxon's signed-rank test was used to compare the values before and after treatment. A $P$ value of $<0.05$ was used to denote statistical significance.

\section{Results}

Dexamethasone treatment caused a very small but significant increase in body weight (from 87.4 \pm 7.1 to $88.6 \pm 7.2 \mathrm{~kg} ; P=0.003$ ) but did not affect intrahepatic TG content (before: $5.1 \pm 1.9 \%$; after: $3.6 \pm 0.9 \%$; $P=0.261)$. Morning plasma cortisol concentration decreased by $\sim 50 \%$ after dexamethasone treatment; ACTH, TNF- $\alpha$, and IL6 concentrations remained unchanged (Table 1). Glucose Ra (Fig. 1) and glucose concentration (Table 1) in plasma were not different before or after dexamethasone treatment. FFA Ra in plasma was not affected $(P=0.185)$ by dexamethasone treatment (Fig. 1), but plasma FFA concentration was reduced by $\sim 20 \%$ (Table 1 ). Plasma insulin concentration increased by $\sim 60 \%$ (Table 1 ). Accordingly, the HISI and the ATISI (Fig. 1) declined by $\sim 50$ and $25 \%$, respectively, after dexamethasone treatment, but these differences failed to reach significance at the $P<0.05$ level $(P=0.066$ and 0.086 respectively).

There were no significant differences $(P \geq 0.3)$ in VLDL-TG and VLDL-apoB-100 secretion rates and MRTs before or after dexamethasone treatment (Fig. 2). The contribution of systemic plasma FFA and nonsystemic fatty acids to total VLDL-TG production was not affected by dexamethasone treatment: systemic plasma FFA 
Table 1 Metabolic profile before and after 3 weeks of low-dose dexamethasone treatment. Values are mean \pm S.E.M. or median (quartiles).

\begin{tabular}{lccc}
\hline & Before & After & $P$ value \\
\hline Glucose $(\mathrm{mg} / \mathrm{dl})$ & $94.1 \pm 3.0$ & $92.3 \pm 1.8$ & 0.451 \\
Insulin $(\mathrm{mU} / \mathrm{ml})$ & $8.5 \pm 1.7$ & $11.9 \pm 2.3$ & 0.048 \\
Free fatty acids $(\mu \mathrm{mol} / \mathrm{l})$ & $506 \pm 47$ & $390 \pm 40$ & 0.003 \\
Total cholesterol $(\mathrm{mg} / \mathrm{dl})$ & $164 \pm 10$ & $168 \pm 15$ & 0.514 \\
HDL-cholesterol $(\mathrm{mg} / \mathrm{dl})$ & $45.9 \pm 2.8$ & $55.1 \pm 4.6$ & 0.037 \\
LDL-cholesterol $(\mathrm{mg} / \mathrm{dl})$ & $99.4 \pm 8.9$ & $96.6 \pm 10.7$ & 0.620 \\
Total TG $(\mathrm{mg} / \mathrm{dl})$ & $91.8 \pm 20.1$ & $83.8 \pm 17.3$ & 0.330 \\
VLDL-TG $(\mathrm{mg} / \mathrm{dl})$ & $30.9 \pm 4.9$ & $29.3 \pm 7.0$ & 0.820 \\
Total apoB-100 $(\mathrm{mg} / \mathrm{dl})$ & $66.0 \pm 8.3$ & $65.8 \pm 8.9$ & 0.980 \\
VLDL-apoB-100 $(\mathrm{mg} / \mathrm{dl})$ & $2.6 \pm 0.5$ & $2.6 \pm 0.6$ & 0.896 \\
Tumor necrosis & $0.8(0.7-1.2)$ & $1.0(0.4-1.2)$ & 0.374 \\
$\quad$ factor $\alpha(\mathrm{pg} / \mathrm{ml})$ & & & \\
Interleukin $6(\mathrm{pg} / \mathrm{ml})$ & $2.7(1.6-3.2)$ & $2.4(1.5-4.5)$ & 0.214 \\
Cortisol $(\mu \mathrm{g} / \mathrm{dl})$ & $5.76 \pm 0.49$ & $2.97 \pm 0.66$ & 0.008 \\
ACTH $(\mathrm{pg} / \mathrm{ml})$ & $21.8 \pm 2.0$ & $15.2 \pm 3.6$ & 0.125 \\
\hline
\end{tabular}

accounted for $58 \pm 4 \%$ of all fatty acids in VLDL-TG before and $55 \pm 5 \%$ after dexamethasone treatment $(P=0.485)$.

The concentrations of total and LDL-cholesterol, total and VLDL-TG, and total and VLDL-apoB-100 in plasma were not affected by dexamethasone treatment, whereas plasma HDL-cholesterol concentration increased by $\sim 20 \%$ (Table 1). VLDL, intermediate-density lipoprotein (IDL), and LDL particle concentrations and average particle sizes were not different before or after dexamethasone treatment, but total HDL particle concentration increased by $\sim 20 \%$, mainly because of more medium-sized particles that therefore did not affect the average HDL size (Table 2).

\section{Discussion}

Endogenous glucocorticoid excess has been proposed to be at least partially responsible for the metabolic abnormalities associated with obesity $(2,3)$. In this study, we evaluated the effect of treatment using dexamethasone, a synthetic glucocorticoid, on metabolic function in overweight and obese individuals with normal plasma cortisol concentrations at baseline. In our study, we chose to administer dexamethasone orally to induce glucocorticoid excess not only in the systemic circulation but also in the portal system because the metabolic syndrome in obese persons is characterized by increased glucocorticoid signaling in peripheral and visceral adipose tissues due to hyperactivity of the hypothalamic-pituitary-adrenal axis and increased $11 \beta$-hydroxysteroid dehydrogenase type 1 activity in adipose tissue (peripheral and visceral) and possibly also liver; in addition, portal vein cortisone provides a substrate for liver cortisol production $(27,28,29)$. We found that dexamethasone treatment led to a slight increase in body weight and a slight decrease in hepatic and adipose tissue insulin sensitivity (evident by the unchanged glucose and FFA Ra in plasma in the face of greater plasma insulin concentration) but had no effect on intrahepatic TG content and basal rates of hepatic VLDL-TG and VLDL-apoB-100 secretion, VLDL-TG and VLDL-apoB-100 mean residence times in the circulation, plasma TG and LDL-cholesterol concentrations, and circulating lipoprotein particle sizes. In addition, dexamethasone treatment had some beneficial metabolic effects by increasing plasma HDL-cholesterol and particle concentrations.

The adverse effects of glucocorticoids on body weight and insulin sensitivity are well established $(3,30)$ and confirmed in our study. Nevertheless, plasma glucose and FFA Ra into plasma, which are tightly controlled by insulin $(31,32)$, did not increase in response to dexamethasone, presumably due to a compensatory increase in insulin secretion (33). This is consistent with the results from the previous studies, which demonstrated that large doses of glucocorticoids (30-50 mg/day prednisone, equivalent to six to ten times the dose of dexamethasone given in our study (14)) do not affect adipose tissue lipolysis and hepatic glucose production $(34,35)$. However, others have shown that acutely, within hours to a few days, glucocorticoid administration at even larger doses increases glucose and FFA Ra in plasma $(4,5,33,36)$. This may be the result of a dose-dependent effect of glucocorticoids on pancreatic $\beta$-cell function, leading to proportionally smaller compensatory increases in circulating insulin (37). Subclinical hypercortisolemia per se therefore does not disturb plasma glucose and FFA homeostasis. However, in susceptible persons, it might accelerate the progression of insulin resistance to type 2 diabetes mellitus (38).
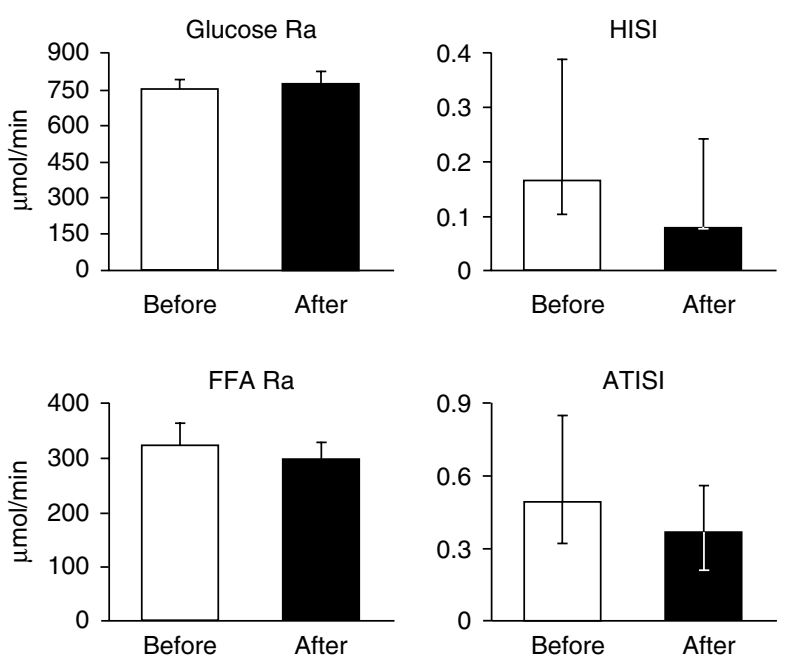

Figure 1 Glucose and FFA Ra in plasma and hepatic (HISI) and adipose tissue (ATISI) insulin sensitivity index before and after dexamethasone treatment. Data are mean \pm S.E.M. (glucose and FFA Ra) or medians with quartiles (HISI and ATISI). There was a trend for a decrease in HISI and ATISI, but it did not reach statistical significance at the $P \leq 0.05$ level $(P=0.066$ and 0.086 respectively). 

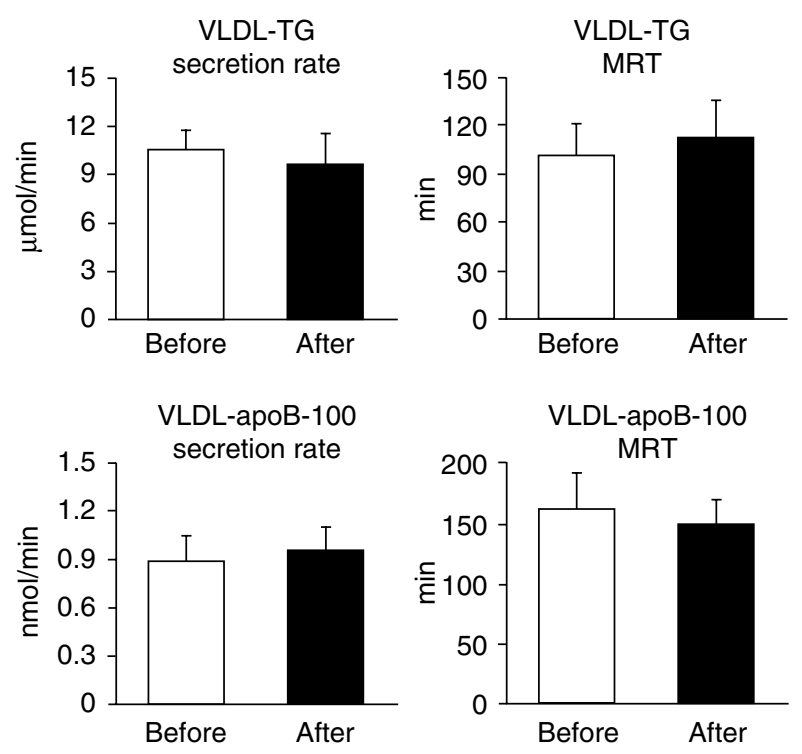

Figure 2 VLDL, TG, and VLDL apoB-100 secretion rates and MRT in plasma before and after dexamethasone treatment. Data are mean \pm S.E.M.

We are not aware of any studies that evaluated the effects of exogenous glucocorticoid administration on VLDL kinetics in human subjects, except in those with Cushing's syndrome which found that hepatic VLDL-TG production rate is greater in patients with endogenous hypercortisolemia than in healthy subjects (39). These results, however, are difficult to interpret because of multiple potential confounding factors. Our data suggest that low-dose glucocorticoid administration does not stimulate VLDL-TG or VLDL-apoB-100 secretion from the liver and does not adversely affect plasma TG or apoB-100 homeostasis. In addition, the low-dose dexamethasone treatment used in our study increased plasma HDL-cholesterol concentration by $\sim 20 \%$. This was linked to an increase in the total number of circulating HDL particles, predominantly due to increased medium-sized HDL. These findings are consistent with the results from studies in which glucocorticoids were administered as anti-inflammatory and immunosuppressive agents in patients with rheumatic and pulmonary diseases, which indicate that the glucocorticoid-induced increase in HDLcholesterol concentration $(9,10,11)$ is predominantly due to an increase in the $\mathrm{HDL}_{2}$ subfraction (large- and medium-sized HDL) but not in the $\mathrm{HDL}_{3}$ subfraction (small HDL) $(40,41)$.

The mechanisms responsible for the glucocorticoidinduced increase in HDL particle and HDL-cholesterol concentrations are not entirely clear but most likely include decreased cholesterol ester transfer protein expression and increased secretion of apoA-I (the main protein of HDL particles) from the liver (42). We can exclude the possibility of reduced cholesterol transfer to VLDL (in exchange for TG) due to faster removal of
VLDL-TG from the circulation, which has been proposed to occur in response to glucocorticoid-induced stimulation of lipoprotein lipase (LPL) $(43,44,45)$. In our study, dexamethasone administration had no effect on VLDL-apoB-100 or VLDL-TG mean residence times in the circulation. The apparent discrepancy between the dexamethasone-induced stimulation of ex vivo measured adipose tissue LPL in humans and rodents $(43,44,45)$ and our results are most likely related to the fact that ex vivo-measured tissue or plasma LPL mass or activity provide information regarding the maximal capacity for LPL-mediated lipolysis but do not reflect in vivo LPL activity that is affected by a variety of factors such as apolipoproteins (apoE and apoCs) present on the particle surface, as well as local FFA concentration, blood flow through the tissue capillary beds, etc. (46). In fact, marked differences in post-heparin plasma LPL activity have been demonstrated in the absence of detectable changes in plasma TG clearance rates in vivo (47).

We cannot exclude the possibility that the low dose of dexamethasone used or the short duration of our study limited the metabolic adverse effects. However, we consider it unlikely because we did observe a decrease in insulin sensitivity and an increase in HDL concentration, which are the commonly observed metabolic side effects of glucocorticoid pharmacotherapy. Furthermore, longer duration of treatment and/or using pharmacological doses would most likely have led to confounding influences $(2,3)$. Dexamethasone treatment lowered endogenous cortisol release and may have also reduced endogenous androgen production. Nevertheless, total glucocorticoid activity (endogenous plus exogenous) was greater with dexamethasone treatment and it is unlikely that changes in androgen availability confounded our results because we have shown that an approximately sevenfold change in plasma testosterone concentration and the normal physiological variations

Table 2 Lipoprotein particle concentrations and sizes before and after 3 weeks of low-dose dexamethasone treatment. Values are mean \pm S.E.M. or median (quartiles).

\begin{tabular}{lccc}
\hline & Before & After & $\boldsymbol{P}$ value \\
\hline VLDL particles, & $68.4 \pm 12.2$ & $58.0 \pm 9.2$ & 0.339 \\
$\quad$ total $(\mathrm{nmol} / \mathrm{l})$ & & & \\
Large & $0.55(0.13-0.96)$ & $0.61(0.10-1.39)$ & 0.859 \\
Medium & $26.1 \pm 6.3$ & $20.7 \pm 4.1$ & 0.300 \\
Small & $40.4 \pm 6.1$ & $35.4 \pm 6.2$ & 0.406 \\
Average VLDL size $(\mathrm{nm})$ & $44.4 \pm 1.8$ & $46.9 \pm 3.2$ & 0.274 \\
IDL particles $(\mathrm{nmol} / \mathrm{l})$ & $26.9 \pm 12.4$ & $28.9 \pm 13.3$ & 0.833 \\
LDL particles $(\mathrm{nmol} / \mathrm{l})$ & $1139(853-1327)$ & $1043(900-1500)$ & 0.260 \\
Large & $448 \pm 47$ & $478 \pm 40$ & 0.416 \\
Small & $600(405-859)$ & $668(477-910)$ & 0.441 \\
Average LDL size $(\mathrm{nm})$ & $21.2 \pm 0.2$ & $21.1 \pm 0.1$ & 0.564 \\
HDL particles $(\mu \mathrm{mol} / \mathrm{l})$ & $33.7 \pm 2.2$ & $41.4 \pm 4.2$ & 0.023 \\
Large & $7.8(5.7-11.1)$ & $8.9(6.6-17.3)$ & 0.066 \\
Medium & $2.5 \pm 0.6$ & $6.7 \pm 1.5$ & 0.010 \\
Small & $22.9 \pm 1.5$ & $23.5 \pm 2.0$ & 0.769 \\
Average HDL size $(\mathrm{nm})$ & $9.1 \pm 0.1$ & $9.1 \pm 0.1$ & 0.939 \\
\hline
\end{tabular}


in plasma progesterone concentration do not affect VLDL kinetics in obese women $(48,49)$.

In summary, low-dose dexamethasone treatment in obese subjects led to a small decrease in insulin sensitivity, which was compensated for by an increase in insulin secretion and an increase in HDL-cholesterol and HDL particle concentrations in plasma but had no effect on intrahepatic TG content, glucose or FFA Ra in plasma, or pro-atherogenic lipoprotein concentrations or VLDL metabolism. Subclinical hypercortisolemia, therefore, is unlikely to be responsible for the development of the metabolic complications associated with obesity.

\section{Declaration of interest}

The authors declare that there is no conflict of interest that could be perceived as prejudicing the impartiality of the research reported.

\section{Funding}

This publication was made possible by NIH grants HD 57796, AG 31297, DK 56341 (Nutrition and Obesity Research Center), RR-024992 (Washington University School of Medicine Clinical Translational Science Award), and RR-00954 (Biomedical Mass Spectrometry Resource).

\section{Author contribution statement}

X Wang, D N Reeds, and J Kampelman conducted the experiments and researched the data; X Wang, F Magkos, B W Patterson, and B Mittendorfer analyzed and interpreted the data; X Wang, F Magkos, and B Mittendorfer wrote the manuscript; all authors edited the manuscript; B Mittendorfer designed the study and had the overall supervision.

\section{Acknowledgements}

The authors thank Freida Custodio, Jennifer Shew, and Dr Adewole Okunade for their technical assistance, the staff of the Clinical Research Unit for their help in performing the studies, and the study subjects for their participation.

\section{References}

1 Walker BR. Glucocorticoids and cardiovascular disease. European Journal of Endocrinology 2007157 545-559. (doi:10.1530/EJE07-0455)

2 Anagnostis P, Athyros VG, Tziomalos K, Karagiannis A \& Mikhailidis DP. Clinical review: the pathogenetic role of cortisol in the metabolic syndrome: a hypothesis. Journal of Clinical Endocrinology and Metabolism 200994 2692-2701. (doi:10. 1210/jc.2009-0370)

3 Macfarlane DP, Forbes S \& Walker BR. Glucocorticoids and fatty acid metabolism in humans: fuelling fat redistribution in the metabolic syndrome. Journal of Endocrinology 2008197 189-204. (doi:10.1677/JOE-08-0054)

4 Divertie GD, Jensen MD \& Miles JM. Stimulation of lipolysis in humans by physiological hypercortisolemia. Diabetes 199140 1228-1232. (doi:10.2337/diabetes.40.10.1228)

5 Dinneen S, Alzaid A, Miles J \& Rizza R. Metabolic effects of the nocturnal rise in cortisol on carbohydrate metabolism in normal humans. Journal of Clinical Investigation 199392 2283-2290. (doi:10.1172/JCI116832)
6 Abumrad NA \& Klein S. Update on the pathophysiology of obesity. Current Opinion in Clinical Nutrition and Metabolic Care 201013 357-358. (doi:10.1097/MCO.0b013e32833ae702)

7 Arnaldi G, Scandali VM, Trementino L, Cardinaletti M, Appolloni G \& Boscaro M. Pathophysiology of dyslipidemia in Cushing's syndrome. Neuroendocrinology 201092 (Suppl 1) 86-90. (doi:10.1159/000314213)

8 el-Shaboury AH \& Hayes TM. Hyperlipidaemia in asthmatic patients receiving long-term steroid therapy. BMJ 19732 85-86. (doi:10.1136/bmj.2.5858.85)

9 Choi HK \& Seeger JD. Glucocorticoid use and serum lipid levels in US adults: the Third National Health and Nutrition Examination Survey. Arthritis and Rheumatism $2005 \quad 53$ 528-535. (doi:10.1002/art.21329)

10 Ettinger WH, Klinefelter HF \& Kwiterovitch PO. Effect of shortterm, low-dose corticosteroids on plasma lipoprotein lipids. Atherosclerosis 198763 167-172. (doi:10.1016/0021-9150 (87)90117-1)

11 Georgiadis AN, Papavasiliou EC, Lourida ES, Alamanos Y, Kostara C, Tselepis AD \& Drosos AA. Atherogenic lipid profile is a feature characteristic of patients with early rheumatoid arthritis: effect of early treatment - a prospective, controlled study. Arthritis Research \& Therapy 20068 R82. (doi:10.1186/ar1952)

12 Freedman MR, Horwitz BA \& Stern JS. Effect of adrenalectomy and glucocorticoid replacement on development of obesity. American Journal of Physiology 1986250 R595-R607.

13 Mantha L, Palacios E \& Deshaies Y. Modulation of triglyceride metabolism by glucocorticoids in diet-induced obesity. American Journal of Physiology 1999277 R455-R464.

14 Filipsson H, Monson JP, Koltowska-Haggstrom M, Mattsson A \& Johannsson G. The impact of glucocorticoid replacement regimens on metabolic outcome and comorbidity in hypopituitary patients. Journal of Clinical Endocrinology and Metabolism $2006 \mathbf{9 1}$ 3954-3961. (doi:10.1210/jc.2006-0524)

15 Metropolitan Life Insurance Company. 1983 Metropolitan height and weight tables. Statistical Bulletin of the Metropolitan Life Insurance Company $1983642-9$.

16 Magkos F, Patterson BW \& Mittendorfer B. Reproducibility of stable isotope-labeled tracer measures of VLDL-triglyceride and VLDLapolipoprotein B-100 kinetics. Journal of Lipid Research $2007 \mathbf{4 8}$ 1204-1211. (doi:10.1194/jlr.D600048-JLR200)

17 Mittendorfer B, Patterson BW \& Klein S. Effect of weight loss on VLDL-triglyceride and apoB-100 kinetics in women with abdominal obesity. American Journal of Physiology. Endocrinology and Metabolism 2003284 E549-E556. (doi:10.1152/ajpendo. 00379.2002)

18 Otvos JD, Jeyarajah EJ, Bennett DW \& Krauss RM. Development of a proton nuclear magnetic resonance spectroscopic method for determining plasma lipoprotein concentrations and subspecies distributions from a single, rapid measurement. Clinical Chemistry 199238 1632-1638.

19 Magkos F, Mohammed BS \& Mittendorfer B. Effect of obesity on the plasma lipoprotein subclass profile in normoglycemic and normolipidemic men and women. International Journal of Obesity 200832 1655-1664. (doi:10.1038/ijo.2008.164)

20 Patterson BW, Zhao G, Elias N, Hachey DL \& Klein S. Validation of a new procedure to determine plasma fatty acid concentration and isotopic enrichment. Journal of Lipid Research $1999402118-2124$.

21 Patterson BW, Mittendorfer B, Elias N, Satyanarayana R \& Klein S. Use of stable isotopically labeled tracers to measure very low density lipoprotein-triglyceride turnover. Journal of Lipid Research $200243223-233$.

22 Magkos F, Fabbrini E, Korenblat K, Okunade AL, Patterson BW \& Klein S. Reproducibility of glucose, fatty acid and VLDL kinetics and multi-organ insulin sensitivity in obese subjects with nonalcoholic fatty liver disease. International Journal of Obesity 2011 35 1233-1240. (doi:10.1038/ijo.2010.265)

23 Mittendorfer B, Liem O, Patterson BW, Miles JM \& Klein S. What does the measurement of whole-body fatty acid rate of appearance in plasma by using a fatty acid tracer really mean? Diabetes 2003 52 1641-1648. (doi:10.2337/diabetes.52.7.1641) 
24 Matsuda M \& DeFronzo RA. Insulin sensitivity indices obtained from oral glucose tolerance testing: comparison with the euglycemic insulin clamp. Diabetes Care 199922 1462-1470. (doi:10.2337/diacare.22.9.1462)

25 Tripathy D, Almgren P, Tuomi T \& Groop L. Contribution of insulin-stimulated glucose uptake and basal hepatic insulin sensitivity to surrogate measures of insulin sensitivity. Diabetes Care 200427 2204-2210. (doi:10.2337/diacare.27.9.2204)

26 Fabbrini E, Magkos F, Conte C, Mittendorfer B, Patterson BW, Okunade AL \& Klein S. Validation of a novel index to assess insulin resistance of adipose tissue lipolytic activity in obese subjects. Journal of Lipid Research 201253 321-324. (doi:10.1194/jlr. D020321)

27 Basu R, Basu A, Grudzien M, Jung P, Jacobson P, Johnson M, Singh R, Sarr M \& Rizza RA. Liver is the site of splanchnic cortisol production in obese nondiabetic humans. Diabetes $2009 \mathbf{5 8}$ 39-45. (doi:10.2337/db08-1079)

28 Baudrand R, Carvajal CA, Riquelme A, Morales M, Solis N, Pizarro M, Escalona A, Boza C, Perez G, Dominguez A, Arrese M \& Fardella CE. Overexpression of $11 \beta$-hydroxysteroid dehydrogenase type 1 in hepatic and visceral adipose tissue is associated with metabolic disorders in morbidly obese patients. Obesity Surgery 201020 77-83. (doi:10.1007/s11695-009-9937-0)

29 Walker BR \& Andrew R. Tissue production of cortisol by $11 \beta$-hydroxysteroid dehydrogenase type 1 and metabolic disease. Annals of the New York Academy of Sciences $2006 \mathbf{1 0 8 3} 165-184$. (doi:10.1196/annals.1367.012)

30 Pivonello R, De Leo M, Vitale P, Cozzolino A, Simeoli C, De Martino MC, Lombardi G \& Colao A. Pathophysiology of diabetes mellitus in Cushing's syndrome. Neuroendocrinology 201092 (Suppl 1) 77-81. (doi:10.1159/000314319)

31 Jensen MD, Caruso M, Heiling V \& Miles JM. Insulin regulation of lipolysis in nondiabetic and IDDM subjects. Diabetes 198938 1595-1601. (doi:10.2337/diabetes.38.12.1595)

32 Prager R, Wallace P \& Olefsky JM. In vivo kinetics of insulin action on peripheral glucose disposal and hepatic glucose output in normal and obese subjects. Journal of Clinical Investigation $1986 \mathbf{7 8}$ 472-481. (doi:10.1172/JCI112599)

33 Nicod N, Giusti V, Besse C \& Tappy L. Metabolic adaptations to dexamethasone-induced insulin resistance in healthy volunteers. Obesity Research 200311 625-631. (doi:10.1038/oby.2003.90)

34 Gravholt CH, Dall R, Christiansen JS, Moller N \& Schmitz O. Preferential stimulation of abdominal subcutaneous lipolysis after prednisolone exposure in humans. Obesity Research 2002 10 774-781. (doi:10.1038/oby.2002.105)

35 Miyoshi H, Shulman GI, Peters EJ, Wolfe MH, Elahi D \& Wolfe RR. Hormonal control of substrate cycling in humans. Journal of Clinical Investigation 1988 81 1545-1555. (doi:10.1172/JCI113487)

36 Dirlewanger M, Schneiter PH, Paquot N, Jequier E, Rey V \& Tappy L. Effects of glucocorticoids on hepatic sensitivity to insulin and glucagon in man. Clinical Nutrition 200019 29-34. (doi:10. 1054/clnu.1999.0064)

37 Matsumoto K, Yamasaki H, Akazawa S, Sakamaki H, Ishibashi M, Abiru N, Uotani S, Matsuo H, Yamaguchi Y, Tokuyama K \& Nagataki S. High-dose but not low-dose dexamethasone impairs glucose tolerance by inducing compensatory failure of pancreatic $\beta$-cells in normal men. Journal of Clinical Endocrinology and Metabolism 199681 2621-2626. (doi:10.1210/jc.81.7.2621)

38 Wajngot A, Giacca A, Grill V, Vranic M \& Efendic S. The diabetogenic effects of glucocorticoids are more pronounced in low- than in high-insulin responders. PNAS $1992 \mathbf{8 9}$ 6035-6039. (doi:10.1073/pnas.89.13.6035)
39 Taskinen MR, Nikkila EA, Pelkonen R \& Sane T. Plasma lipoproteins, lipolytic enzymes, and very low density lipoprotein triglyceride turnover in Cushing's syndrome. Journal of Clinical Endocrinology and Metabolism 198357 619-626. (doi:10.1210/ jcem-57-3-619)

40 Garcia-Gomez C, Nolla JM, Valverde J, Narvaez J, Corbella E \& Pinto X. High HDL-cholesterol in women with rheumatoid arthritis on low-dose glucocorticoid therapy. European Journal of Clinical Investigation 200838 686-692. (doi:10.1111/j.13652362.2008.01994.x)

41 Salazar A, Mana J, Pinto X, Argimon JM, Hurtado I \& Pujol R. Corticosteroid therapy increases HDL-cholesterol concentrations in patients with active sarcoidosis and hypoalphalipoproteinemia. Clinica Chimica Acta 2002320 59-64. (doi:10.1016/S00098981(02)00046-3)

42 Staels B, van Tol A, Chan L, Verhoeven G \& Auwerx J. Variable effects of different corticosteroids on plasma lipids, apolipoproteins, and hepatic apolipoprotein mRNA levels in rats. Arteriosclerosis and Thrombosis 199111 760-769. (doi:10.1161/01.ATV.11. 3.760)

43 Fried SK, Russell CD, Grauso NL \& Brolin RE. Lipoprotein lipase regulation by insulin and glucocorticoid in subcutaneous and omental adipose tissues of obese women and men. Journal of Clinical Investigation 199392 2191-2198. (doi:10.1172/ JCI116821)

44 Qi D, Pulinilkunnil T, An D, Ghosh S, Abrahani A, Pospisilik JA, Brownsey R, Wambolt R, Allard M \& Rodrigues B. Single-dose dexamethasone induces whole-body insulin resistance and alters both cardiac fatty acid and carbohydrate metabolism. Diabetes 200453 1790-1797. (doi:10.2337/diabetes.53.7.1790)

45 Bagdade JD, Yee E, Albers J \& Pykalisto OJ. Glucocorticoids and triglyceride transport: effects on triglyceride secretion rates, lipoprotein lipase, and plasma lipoproteins in the rat. Metabolism 197625 533-542. (doi:10.1016/0026-0495(76)90007-X)

46 Magkos F. Basal very low-density lipoprotein metabolism in response to exercise: mechanisms of hypotriacylglycerolemia. Progress in Lipid Research 200948 171-190. (doi:10.1016/j. plipres.2009.02.003)

47 Duncan GE, Perri MG, Theriaque DW, Hutson AD, Eckel RH \& Stacpoole PW. Exercise training, without weight loss, increases insulin sensitivity and post heparin plasma lipase activity in previously sedentary adults. Diabetes Care 200326 557-562. (doi:10.2337/diacare.26.3.557)

48 Wang X, Smith GI, Patterson BW, Reeds DN, Kampelman J, Magkos F \& Mittendorfer B. Testosterone increases the muscle protein synthesis rate but does not affect very-low-density lipoprotein metabolism in obese premenopausal women. American Journal of Physiology. Endocrinology and Metabolism $20123 \mathbf{3 0 2}$ E740-E746. (doi:10.1152/ajpendo.00533.2011)

49 Magkos F, Patterson BW \& Mittendorfer B. No effect of menstrual cycle phase on basal very-low-density lipoprotein triglyceride and apolipoprotein B-100 kinetics. American Journal of Physiology. Endocrinology and Metabolism 2006291 E1243-E1249. (doi:10.1152/ajpendo.00246.2006)

Received 28 February 2012

Revised version received 11 May 2012

Accepted 22 May 2012 